\title{
Culprits in the degradation of cyclin E apprehended
}

\author{
Jeffrey T. Winston, Claire Chu, and J. Wade Harper ${ }^{1}$ \\ Verna and Marrs McLean Department of Biochemistry, Baylor College of Medicine, Houston, Texas 77030 USA
}

Critical events in the life of a cell require that the flux through particular regulatory pathways be abruptly and irreversibly altered in response to intracellular and extracellular signals. The central role played by reversible phosphorylation in controlling signaling pathways is well established, but in the last few years, ubiquitinmediated proteolysis has emerged as an equally important, and in some cases collaborative, partner in the control of regulatory processes in the cell. Ubiquitination, typically in the form of polyubiquitination, serves as a signal for destruction of the tagged protein by the $26 \mathrm{~S}$ proteasome. Because the proteolytic event itself is very rapid, it is the process of ubiquitination that is rate limiting and highly regulated. Protein ubiquitination involves a cascade of ubiquitin transfer reactions and requires three components: E1, E2, and E3 (Hershko and Ciechanover 1998). In the first step, a ubiquitin-activating enzyme (E1) is charged with ubiquitin through a thiol-ester linkage. This ubiquitin is then transferred to one of a dozen or so ubiquitin conjugating enzymes (E2) also as a thiol-ester. The ubiquitin is finally transferred from the E2 to one or more lysine residues in the substrate with the aid of an E3 ubiquitin ligase. Multiple rounds of ubiquitin conjugation with the initial ubiquitin as the recipient lead to polyubiquitin chain formation. In essence, E3s function as substrate-specific adaptors by simultaneously binding substrate and the E2, although in some cases, E3s may also serve as an intermediate in the ubiquitin transfer process.

Given that there are a large and diverse number of proteins whose abundance in the cell is controlled by ubiquitin-mediated proteolysis, how is sufficient diversity generated such that E3s selectively recognize only one or a few substrates? The answer to this question appears to be a superfamily of multicomponent E3s that dock substrates with a core ubiquitin-conjugating system via modular, substrate-specific adaptor proteins. The core-conjugating apparatus in several E3s includes a member of the Cullin/Cdc53 family of proteins first identified in budding yeast and Caenorhabditis elegans (Kipreos et al. 1996; Mathias et al. 1996; Willems et al. 1996). New work, including a recent paper in Genes and

${ }^{1}$ Corresponding author.

E-MAIL jharper@bcm.tmc.edu; FAX (713) 796-9438.
Development, implicates two distinct members of the Cullin family-Cul3 and Cul1-in the ubiquitin-mediated destruction of mammalian cyclin $\mathrm{E}$, an activator of $\mathrm{Cdk} 2$ and an essential regulator of the $\mathrm{G}_{1} / \mathrm{S}$ transition (Singer et al. 1999; Dealy et al. 1999; Wang et al. 1999). The work reveals an unanticipated link between Cul3 and cell cycle control, and provides the first evidence that distinct Cullin complexes function in concert to control the levels of a single target protein. The requirement of Cul3 for embryonic development (Singer et al. 1999) provides yet another reminder of the importance of ubiquitin-mediated proteolysis in coordinating crucial events in the organism.

\section{Cullins and ubiquitin ligases}

There are six known Cullin genes in mammals, five in $C$. elegans, and three in budding yeast. Apc2, a subunit of the anaphase-promoting complex responsible for ubiquitination of mitotic regulators, is distantly related to Cullins and shares homology with Cullins in a region implicated in E2 binding (Zachariae et al. 1998). The best understood Cullin family member is Cull and its budding yeast homolog Cdc53, which are components of a class of E3s referred to as SCF ubiquitin ligases (Feldman et al. 1997; Skowyra et al. 1997; Patton et al. 1998a). SCF complexes (Fig. 1) contain $\underline{S} k p 1, \underline{C} d c 53 / C u l 1$, the Cullin-interacting protein Rbx1 (also known as Hrtl and Roc1), and a member of the F-box family of proteins. F-box proteins (Bai et al. 1996) function as modular adaptors by binding simultaneously to substrate through carboxy-terminal protein-protein interaction motifs and to Skp1 via the F-box motif. Skp1, in turn, serves as an adaptor to link F-box proteins with the core-conjugating system composed of Cdc53, Rbx1, and the E2 Cdc34 (Feldman et al. 1997; Skowyra et al. 1997, 1999; Patton et al. 1998a; Kamura et al. 1999; Ohta et al. 1999; Seol et al. 1999). The SCF pathway was elucidated primarily as a result of an effort to understand how phosphorylation controls the levels of cyclins and Cdk inhibitors in budding yeast. We now know that the SCF pathway is responsible for controlling much of the phosphorylationdependent ubiquitination in the cell, and is not limited to cell cycle regulators. The phosphorylation-dependent nature of SCF function rests on the fact that F-box proteins bind their substrates in a phosphorylation-depen- 
Figure 1. Modular ubiquitin ligases target diverse substrates for degradation. The prototypical SCF complex contains Rbxl/ Roc1, Skp1, Cdc53/Cul1, and an F-box protein. Analogous proteins assemble with parallel architecture in the Elongin $\mathrm{B} / \mathrm{C}$, Cul2, SOCS-box protein complex. The third member of the cullin family Cul3 has no known partners for substrate targeting. The model shows speculative Skp1- and Fbox-like adapter proteins that hypothetically link cyclin E to Cul3. Another modular ubiquitin ligase, the anaphase-promoting complex, triggers mitotic progression with the Cullin and Rbx1-related proteins, Apc2 and Apc11, respectively. The use of different substrate receptors in complexes with distinct Cullin ubiquitin ligase complexes may underlie the diversity of regulated ubiquitination.

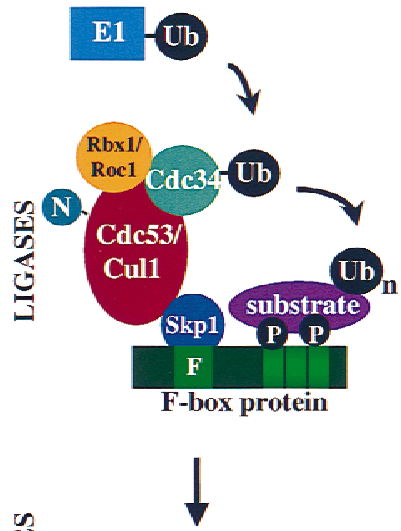

Clns, Sic1, Far1, p27

IKB $\alpha, \beta$-catenin, Gcn 4 Cdc6, Swe1, Gic2

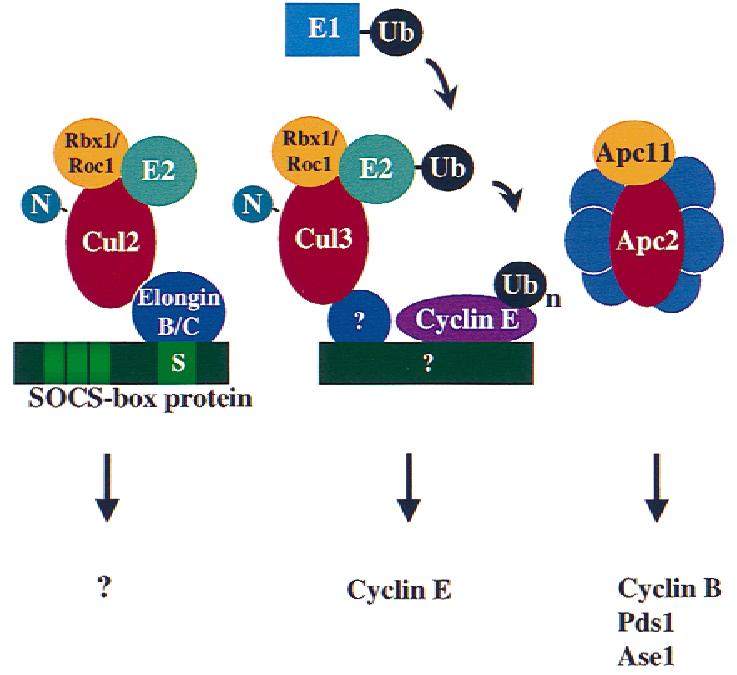

dent manner. In budding yeast, $\mathrm{SCF}^{\mathrm{Cdc} 4}$ has been implicated in the destruction of the Cdk inhibitors Sicl and Farl and the DNA replication control protein Cdc6, among others (for review, see Patton et al. 1998b; Koepp et al. 1999). In mammalian cells, $\mathrm{SCF}^{\mathrm{Skp} 2}$ has been implicated in ubiquitination of the Cdk inhibitor p27 and the transcriptional control protein E2F-1 (Carrano et al. 1999; Marti et al. 1999; Sutterluty et al. 1999; Tsvetkov et al. 1999), whereas the SCF $^{\beta-T R C P}$ complex is responsible for ubiquitination of IкB $\alpha$ and $\beta$-catenin (Jiang and Struhl 1998; Yaron et al. 1998; Spencer et al. 1999; Winston et al. 1999; for review, see Maniatis 1999). Moreover, both Skp1 and Cul1 are required for centriole separation in Xenopus extracts, suggesting a role for proteolysis in centrosome duplication (Freed et al. 1999). There are a large number of F-box proteins, 15 in budding yeast, 60 in C. elegans (Bai et al. 1996; Patton et al. 1998b) and at least 50 in mammalian cells (Cenciarelli et al. 1999; Winston et al. 199a), suggesting that the SCF pathway will control ubiquitination of a large number of proteins.

In contrast with Cul1, relatively little is known about other Cullin family members, although emerging data suggest that these too will be components of modular ubiquitin ligase systems (Fig. 1). Cul2 is associated with elongin $C$, which shares sequence similarity with Skp1. Elongin $\mathrm{C}$, in turn, is bound to the ubiquitin-like protein elongin B (for review, see Kaelin et al. 1998; Tyers and Willems 1999), although the relevance of this is not known at present. Interestingly, elongin $\mathrm{C}$ interacts with a large family of proteins and, in this way, is analogous to Skp1 (Hilton et al. 1998; Kamura et al. 1998; Zhang et al. 1999). This family of proteins is referred to as SOCS-box proteins because the first recognized family members were identified as suppressors of $\underline{c} y$ tokine signaling, but we now know that other proteins, including the von Hippel-Lindau (VHL) tumor suppressor protein and elongin A, are also members of this family (Kamura et al. 1998; Zhang et al. 1999). The SOCS box was initially identified as a sequence motif conserved among the family, but we now know that it contains within it a motif called the $\mathrm{BC}$ box that interacts with elongin $\mathrm{C}$ (Fig. 1). SOCS-box proteins, like F-box proteins, frequently contain additional protein-protein interaction domains that may serve to link them to possible substrates (Fig. 1). Interestingly, the sequences of elongin $\mathrm{C}$ and the $\mathrm{BC}$ box in elongin A are related to those of Skp1 and the F box, respectively (Bai et al. 1996), and a Skp1/F-box structure can easily be modeled on that of the elongin B/C-VHL complex determined crystallographically (Stebbins et al. 1999). Consistent with the involvement of Cul2 in ubiquitination, VHL/elonginB/C/Cul2 complexes display a ubiquitin ligase activity in vitro (Lisztwan et al. 1999), although targets for Cul2-based ligases have yet to be identified. Additional evidence to suggest that Cullins will generally be involved in ubiquitination comes from the finding that all Cullin family members as well as Apc2 interact with a member of the Rbx1/Roc1/Apc11 family of proteins (Zaccharie et al. 1998; Kamura et al. 1999; Ohta et al. 1999). These proteins contain a RING$\mathrm{H} 2$ finger domain, and in the case of Cull/Cdc53 complexes, ubiquitination activity toward both yeast $\mathrm{G}_{1} \mathrm{cy}$ clins and Sic1 requires the presence of Rbx1/Roc1 proteins in the complex (Kamura et al. 1999; Seol et al. 1999; Skowyra et al. 1999). At least one role of the Cdc53/Rbx1 complex is to facilitate recruitment of the E2 and available data indicate that interaction of the E2 Cdc34 with the Cdc53/Rbx1 complex serves to allosterically activate its intrinsinc conjugating activity (Skowyra et al. 1999; Soel et al. 1999). This analogy extends to the essential APC subunit Apc11 (Zaccharie et al. 1998), which assembles with Apc2 in transfected cells and can activate the E2 Ubc5 in vitro (Ohta et al. 1999). Given what we know about the SCF pathway and the emerging Cul2 pathway, it is clear that much is to be learned through analysis of the more poorly studied Cullin proteins. The identification of a substrate is an important first step in this process and this is what has been accomplished with the finding that the level of cyclin $\mathrm{E}$ is controlled, at least in part, through a Cul3 pathway. 


\section{Cyclin E ubiquitination}

Cyclin $\mathrm{E}$ is a rate-limiting component of the machinery that controls S-phase entry and centrosome duplication in multicellular eukaryotes. Periodic accumulation of cyclin $E$ protein during the $G_{1}$ and $S$ phases of the cell cycle is achieved in part by E2F-dependent transactivation of the cyclin E gene (for review, see Dyson 1998) and by ubiquitin-mediated destruction (Clurman et al. 1996; Won and Reed 1996). Rapid turnover of cyclin E ensures that the protein levels reflect mRNA levels, therebymaintaining cyclin $\mathrm{E}$ below the threshold required for activation of the kinase partner, $\mathrm{Cdk} 2$, when cyclin $\mathrm{E}$ transcription is low. The importance of maintaining the appropriate levels od cyclin $E$ during $G_{1}$ is indicated by the finding that inappropriately high levels of cyclin $\mathrm{E} / \mathrm{Cdk} 2$ can accelerate $\mathrm{G}_{1}$ progression and S-phase entry, and can activate DNA replication in the absence of mitogens in fibroblasts (Ohtsubo and Roberts 1993; Resnizky and Reed 1995; Connell-Crowley et al. 1998; Leone et al. 1999). In addition, prolonged cyclin E expression can lead to chromosome instability (Spruck et al. 1999). Thus, ubiquitin-mediated proteolysis provides a mechanism for resetting cyclin E levels after passage through the $G_{1} / S$ transition and for maintaining karyotypic stability.

Two distinct forms of cyclin E appear to be targets for ubiquitination and rapid turnover, free cyclin $\mathrm{E}$ (i.e., cyclin $\mathrm{E}$ that is not associated with Cdk2), and a phosphorylated form of cyclin $\mathrm{E}$ that results from its interaction with Cdk2 (Clurman et al. 1996; Won and Reed 1996). Free forms of cyclin E, such as that produced when the cyclin box is mutated or when cyclin $\mathrm{E}$ is expressed in excess of its Cdk2 partner, are not phosphorylated, yet are highly unstable and accumulate as ubiquitin conjugates when the proteasome is inhibited. Interestingly, association of free cyclin E with Cdk2 (or a catalytically inactive Cdk2 subunit) promotes its stabilization (Clurman et al. 1996), suggesting that in certain contexts, Cdk2 binding can protect against cyclin E ubiquitination. However, mutation of a particular autophosphorylation site on cyclin E, T380, stabilizes the Cdk-bound form of cyclin E while having no effect on the stability of cyclin E not bound to Cdk2 (Clurman et al. 1996; Won and Reed 1996). Taken together, these data indicate that phosphorylation of cyclin E by an associated Cdk2 subunit is required for ubiquitination of cyclin $\mathrm{E}$ when bound to Cdk2 and suggests that both phosphorylationdependent and independent mechanisms are at work to control the overall levels of cyclin E.

This situation has parallels in budding yeast in which the $\mathrm{G}_{1}$ cyclins, $\mathrm{Cln} 1$ and $\mathrm{Cln} 2$, are also controlled by both phosphorylation-dependent and independent modes of ubiquitin-mediated destruction (Lanker et al. 1995). The best understood pathway is the phosphorylation-dependent pathway, whereby phosphorylation of Cln1 allows its association with and ubiquitination by the SCF ${ }^{\mathrm{Grr} 1}$ complex (Seol et al. 1999; Skowyra et al. 1998, 1999). Unlike cyclin E, in which a single phosphorylation event seems to be key, several autophos- phorylation sites in Cln2 are required to confer instability on the protein in vivo (Lanker et al. 1996). Evidence for a second Cln destruction pathway comes from the finding that a mutant form of $\mathrm{Cln} 2$ that does not bind Cdc28 is also unstable, but as with cyclin E, mutation of Cdk phosphorylation sites has no effect on its intrinsic stability (Lanker et al. 1996). Thus, dual modes of $\mathrm{G}_{1}$ cyclin turnover are evolutionarily conserved, suggesting that both pathways are important for controlling the levels of cyclins in a normal cell cycle.

\section{Linking Cul3 and Cul1 to cyclin E turnover}

In an attempt to identify components involved in ubiquitination of free cyclin E, Singer et al. (1999) used a two-hybrid approach to look for proteins that would interact with a cyclin-box point mutant of cyclin E, but not with wild-type cyclin E, and found none other than Cul3. Two lines of biochemical evidence suggest that Cul3 may be a core component of an E3 ubiquitin ligase complex that targets free cyclin E for destruction. First, Cul3 physically associates with cyclin E in mammalian cells, as would be expected if $\mathrm{Cul} 3$ was a component of the cyclin E ubiquitin ligase (Singer et al. 1999). Cul3 binding does not require cyclin E phosphorylation at Thr380, and is inhibited under conditions that drive cyclin E/Cdk2 complex formation, as suggested by the twohybrid results. Second, overexpression of Cul3 stimulates the accumulation of cyclin E-ubiquitin conjugates in a phosphorylation-independent manner, thereby demonstrating a critical link between Cul3 and the cellular cyclin E destruction machinery (Singer et al. 1999).

Genetic evidence from $\mathrm{cull}^{-/-}$mice (Singer et al. 1999) is also consistent with the specific involvement of Cul3 in the ubiquitination of cyclin E. Mice homozygous for the cul3 deletion die at or before day 7.5, with disorganized (or in some cases absent) extraembryonic tissues, abnormal development of the trophectoderm, and a failure to undergo proper gastrulation. Importantly, cyclin E levels in $\mathrm{cull}^{-/-}$embryos are elevated in the ectoplacental cone and the extraembryonic ectoderm (but not embryonic ectoderm) relative to wild-type mice, and this increase correlated with a dramatic increase in the number of S-phase cells as determined by BrdU incorporation (Singer et al. 1999). Thus, Cul3 is likely to be directly required for destruction of cyclin $\mathrm{E}$ in specific tissues in the developing mouse embryo. However, it seems unlikely that the developmental defects observed are solely due to cyclin E accumulation, as Cul3 complexes will likely regulate the levels of other proteins in addition to cyclin E.

Evidence of a role for Cull in cyclin E destruction has come from an analysis of mouse embryos lacking Cull (Dealy et al. 1999; Wang et al. 1999). Cul1 is required for embryonic development; cul1 $1^{-/-}$embryos fail to develop past E5.5. However, embryonic ectodermal cells continue to proliferate and incorporate BrdU as late as E6.5. Interestingly, cul1 ${ }^{-/-}$embryos displayed greatly elevated levels of cyclin $\mathrm{E}$, but in contrast to $\mathrm{cull}^{-/-}$embryos, cyclin $\mathrm{E}$ is elevated in every embryonic tissue layer 
(Dealy et al. 1999; Wang et al. 1999). Jointly, these data indicate that there are multiple pathways, both of which contribute to cyclin E turnover, at least in particular cell types, although the Cull pathway may play a more general role.

Although to a certain degree the embryonic lethality phenotypes of the Cull and Cul3 knockouts are similar, this similarity does not extend to the giant trophoblast cells in the placenta. Unlike most cells, trophoblasts undergo multiple (perhaps $>50$ ) rounds of DNA synthesis without an intervening mitosis, resulting in enlarged or giant nuclei. These recurring $S$ phases are accompanied by periodic accumulation of cyclin $\mathrm{E}$. The process of endoreduplication has been studied in greatest detail in Drosophila, in which ectopic expression of cyclin E in the endoreduplicative cells in the salivary gland prevents normal fluctuations in cyclin E protein levels and inhibits S-phase entry (Follette et al. 1998; Weiss et al. 1998). Available evidence indicates that the re-establishment of prereplicative complexes requires inactivation of S-phase Cdk activity (Dahmann et al. 1995). Thus, the persistent activity of cyclin E/Cdk2 activity in trophoblast giant cells may be incompatible with assembly or firing of replication complexes. In the absence of Cul3, trophoblast cells fail to enter $S$ phase and the resulting trophoblast cells contain small nuclei consistent with the absence of rereplication (Singer et al. 1999). In light of these data, it was suggested that the periodic accumulation of cyclin E/Cdk2 activity is somehow disrupted in these cells and that this is responsible for the absence of origin refiring. However, the finding that trophoblasts lacking Cul1, which also accumulate high levels of cyclin E, not only undergo endoreduplication but may even undergo more endoreduplication events than wild-type trophoblasts (Dealy et al. 1999; Wang et al. 1999) suggest that increased levels of cyclin E alone are not responsible for the absence of endoreduplication observed in $\mathrm{cull}^{-/-}$ trophoblasts. It is possible that the difference in phenotypes represents a subtle difference in the forms of cyclin E that are targeted by the two Cullins. One might imagine that accumulation of free cyclin E, the target of Cul3, could inhibit $S$ phase through a dominant-negative effect. Cyclins contain a substrate interaction domain that recognizes RXL motifs found in substrates ranging from the $\mathrm{Rb}$ family of pocket proteins to replication and transcriptional control (for review, see Roberts 1999). Because the cyclin subunit can interact with RXL motifs in the absence of an associated Cdk subunit, one might imagine that accumulation of free cyclin E would lead to the formation of dead-end cyclin-substrate complexes, thereby interfering with the access of active Cdks to key substrates. Alternatively, the phenotypic differences observed between Cul1 and Cul3 may reflect the stabilization of Cul3 targets other than cyclin E. Clearly, further work needs to be done to determine whether periodic fluctuations in cyclin E/Cdk2 activity are maintained in $\mathrm{cull}^{-/-}$trophoblasts through alternative mechanisms such as Cdk inhibitors or, alternatively, whether endocycles in trophoblasts do not require periodic cyclin E activity.

\section{The next phase}

The current work provides biochemical and genetic evidence for the involvement of a Cul3-dependent ubiquitin ligase in turnover of free cyclin E, and genetic evidence for the involvement of Cull in cyclin E turnover (Fig. 2). Given the parallels with $G_{1}$ cyclin ubiquitination in budding yeast, it seems likely that Cull, via an SCF complex, will be involved specifically in phosphorylationdependent cyclin E ubiquitination, although direct evidence for this is lacking at present. As a result of the central role of cyclin $\mathrm{E}$ in $\mathrm{S}$-phase regulation, it is easy to see why there is a need to control the level of active

\footnotetext{
Figure 2. Distinct pathways degrade free and bound $\mathrm{G}_{1}$ cyclins. Cyclin $\mathrm{E}$ ubiquitination occurs through two pathways, depending on its phosphorylation state. Cul3 is required for targeting free Cyclin $\mathrm{E}$ for ubiquitination in a phosphorylation-independent manner. The phosphorylation-dependent mechanism has yet to be identified. A parallel system exists for two modes of regulating stability of the yeast $\mathrm{G}_{1}$ cyclin $\mathrm{Cln} 1$. The critical cell cycle regulators require multiple layers of regulation to achieve the precision required for timely progression through the cell cycle.
}

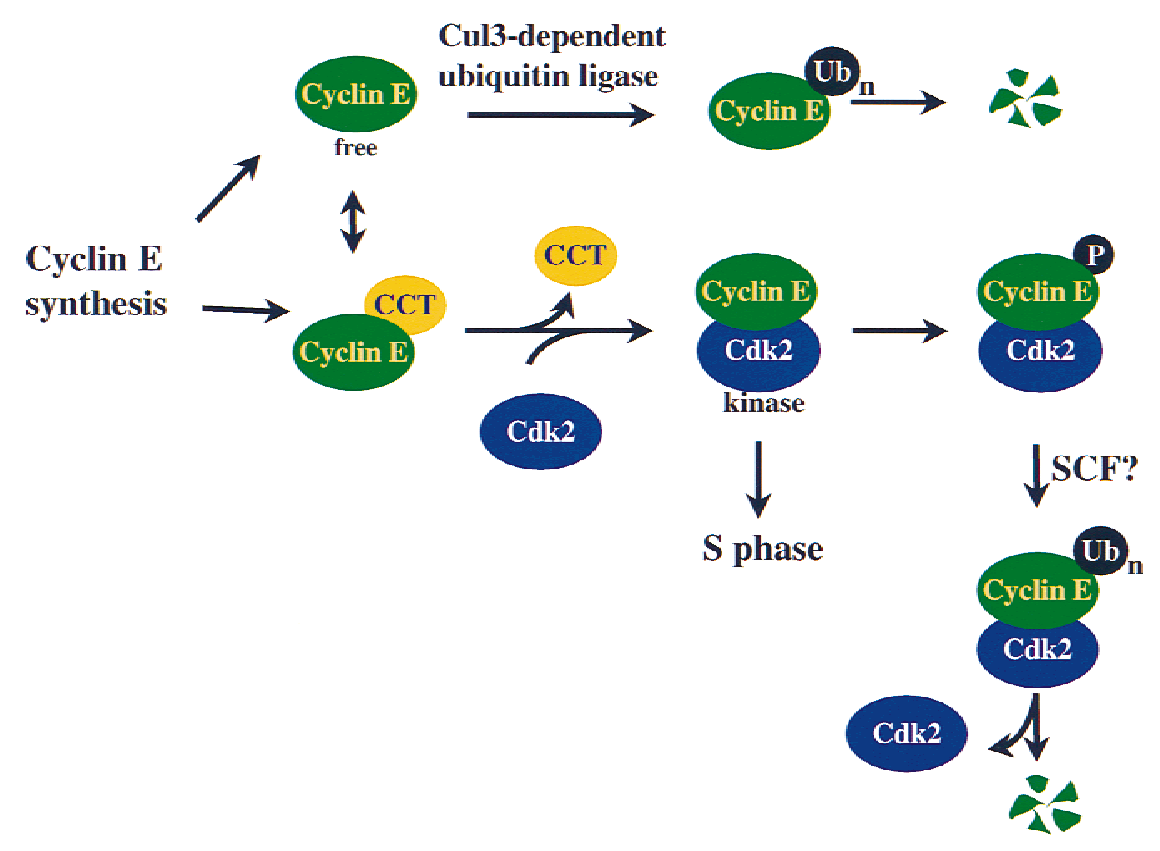


Cdk2 during and after S phase via destruction of phosphorylated cyclin E. However, it is not immediately evident why there is a seemingly independent pathway that controls free cyclin E. The answer may lie in the cell biology of cyclin E maturation, a potentially complex area that has received relatively little attention. Very little is known about the fate of newly synthesized cyclin $\mathrm{E}$, and experiments that monitor the ubiquitination of overexpressed cyclin $\mathrm{E}$ provide scant information about the normal pathways that occur in the cell. For example, we do not know how cyclin $\mathrm{E}$ is partitioned as cells proceed through $\mathrm{G}_{1} / \mathrm{S}$. Does the bulk of the newly synthesized cyclin E end up in complexes with Cdk2, or does a substantial fraction get ubiquitinated through a Cul3 complex, as suggested by the massive accumulation of cyclin E in $\mathrm{cull}^{-/-}$embryos? Cyclin $\mathrm{E}$ has been shown recently to interact with the cytosolic chaperonin CCT (Won et al. 1998), raising the possibility that newly synthesized cyclin $\mathrm{E}$ is partitioned into distinct complexes (Fig. 2). If passage through the CCT complex is required to generate functional cyclin E capable of binding $\mathrm{Cdk} 2$, then cyclin E that eludes the CCT system during the time period associated with progression through $\mathrm{G}_{1}$ may be targeted for destruction by Cul3. In this case, destroying excess cyclin $\mathrm{E}$ might be important for maintaining appropriate levels of Cdk2 activity as cells proceed through the cycle and for resetting the balance of cyclins for the next cell cycle. The possibility that Cul3 is involved in processing of misfolded proteins is also consistent with the finding that mutations in Schizosaccharomyces pombe $\mathrm{Cul} 3, \mathrm{pcu}^{+}{ }^{+}$, render cells sensitive to high temperatures and other stress-inducing agents that have been linked in the past to production of misfolded proteins (Kominami et al. 1998). Although it would appear that at least some of the excess cyclin $\mathrm{E}$ that is generated in $\mathrm{cull}^{-/-}$embryos is potentially active, it is not clear as yet whether there has been a selective accumulation of active, Cdk2-associated cyclin E, or alternatively, an increase in both free and Cdk associated forms.

A second issue that is left unanswered concerns whether Cul3 plays any role in the ubiquitination of cyclin $\mathrm{E}$ that has assembled with Cdk2. Cyclin E that has associated with and been phosphorylated by Cdk2 has two possible fates; it could be recognized by an alternative ubiquitination system such as the SCF, or Cdk2 could dissociate, thereby allowing $\mathrm{Cul} 3$ to recognize this free form of cyclin E (Clurman et al. 1996; Singer et al. 1999). Although there is no clear evidence to support dissociation of cyclin $\mathrm{E}$ from $\mathrm{Cdk} 2$ in response to autophosphorylation, previous tissue culture-based studies have failed to detect ubiquitinated cyclin $\mathrm{E}$ in complexes with Cdk2 under conditions in which proteasome activity is inhibited, despite clear evidence of a phosphorylation-dependent cyclin E ubiquitination pathway (Clurman et al. 1996; Won and Reed 1996). The solution to this apparent paradox may reside in the fact that the regulatory particle of the proteasome contains not only polyubiquitin-recognition factors but a potent, ubiquitin-dependent protein unfolding activity as well (Braun et al. 1999). This unfolding activity is required to allow proteins to enter into the proteolytic cavity of the proteasome. Because experiments examining the fate of cyclin $\mathrm{E}$ are performed in the presence of proteasome inhibitors (Clurman et al. 1996), it is likely that ubiquitinated cyclin E in complexes with Cdk2 is recognized and rapidly unfolded, thereby releasing Cdk2. Under these conditions, only free ubiquitinated cyclin E would be detected. This would explain the accumulation of cyclin E ubiquitin conjugates that are not associated with Cdk2 (Clurman et al. 1996). Singer et al. (1999) provide clear evidence that Cul3 can associate with free cyclin E but it is not clear whether this interaction is direct or not. Given the situation with other Cullin-based ubiquitin ligases, it is reasonable to expect that other components of the Cul3 complex will be identified, including putative substrate recognition proteins. Once these proteins are identified, it will be possible to determine the structural basis for the interaction of cyclin E with its recognition protein in the cullin complex and how Cdk2 binding blocks recognition of cyclin $\mathrm{E}$ by the Cul3 complex.

Finally, to what extent, if any, do the mechanisms controlling D-type cyclin levels parallel those of cyclin $\mathrm{E}$ ? Cyclin D1 expression is rate limiting for $\mathrm{G}_{1}$ progression, at least in part, because of its role in activation of cyclin E expression (Geng et al. 1999). D-type cyclins bind Cdk4, and both the expression of cyclin D and its assembly with the Cdk4 kinase are exquisitely sensitive to mitogen levels (for review, see Sherr and Roberts 1999|. Cyclin D1 is an inherently unstable protein and as such, removal of growth factors that support its expression results in a rapid decline of cyclin D1 pools. Thus, cyclin D1 acts as a sensor, linking extracellular proliferative signals to the basic cell cycle machinery. Like cyclin E, cyclin D1 is destroyed in a ubiquitin- and proteasome-dependent fashion and this requires phosphorylation of Thr286 (Diehl et al. 1997, 1998). In contrast with cyclin E, however, the phosphorylation event in this case is catalyzed in trans by GSK3 $\beta$ and occurs in a spatially and temporally regulated manner (Diehl et al. 1998). Moreover, mutation of Thr286 to a nonphosphorylatable residue stabilizes not only the Cdk4-associated cyclin D but the unbound form as well (Diehl et al. 1997). Hence, the features that characterize the Cul3dependent cyclin $\mathrm{E}$ destruction pathway do not appear to be conserved in the cyclin D1 destruction pathway. This does not exclude the possibility that Cul3 might regulate D1 in a manner distinct from cyclin E; in fact, Cul3 can physically associate with cyclin D1 in vivo (Singer et al. 1999|. However, deletion of the Cul3 gene in mice does not increase cyclin D1 abundance by embryonic day 7.5. It remains to be determined whether Cul3-based ligases influence the abundance of other cell signaling molecules and to what extent the architecture of Cul3 ligases will resemble its cousins. But given what we have learned thus far, it seems likely that analysis of cell cycle regulators will continue to pave the way in the elucidation of ubiquitination pathways that are central to the life of the organism. 


\section{Acknowledgments}

We thank S. Elledge, M. Pagano, C. Sherr, and M. Tyers for stimulating discussions. Work in this laboratory is supported by grants from the National Institute of General Medicine and Aging, the Department of Defense, The Welch Foundation, and the Baylor Specialized Program of Research Excellence in Prostate Cancer.

\section{References}

Bai, C., P. Sen, N. Mathias, K. Hofmann, M. Goebl, J.W. Harper, and S.J. Elledge. 1996. SKP1 connects cell cycle regulation to the ubiquitin proteolysis machinery through a novel motif, the F-box. Cell 86: 263-274.

Braun, B.C., M. Glickman, R. Kraft, B. Dahlmann, P.M. Kloetzel, D. Finley, and M. Schmidt. 1999. The base of the proteasome regulatory particle exhibits chaperone-like activity. Nat. Cell Biol. 1: 221-226.

Caranno, A.C., E. Eytan, A. Hershko, and M. Pagano. 1999. SKP2 is required for ubiquitin-mediated degradation of the CDK inhibitor p27. Nat. Cell Biol. 1: 193-199.

Cenciarelli, C., D.S. Chiaur, D. Guardavaccaro, W. Parks, M. Vidal, and M. Pagano. 1999. Identification of a family of human F-box proteins. Curr. Biol. 9: 1177-1179.

Clurman, B.E., R.J. Sheaff, K. Thress, M. Groudine, and J.M. Roberts. 1996. Turnover of cyclin E by the ubiquitin-proteasome pathway is regulated by cdk2 binding and cyclin phosphorylation. Genes \& Dev. 10: 1979-1990.

Connell-Crowley, L., S.J. Elledge, and J.W. Harper. 1998. G1 cyclin-dependent kinases are sufficient to initiate DNA synthesis in quiescent human fibroblasts. Curr. Biol. 8: 65-68.

Dahmann, C., J.F. Diffley, and K.A. Nasmyth. 1995. S-phasepromoting cyclin-dependent kinases prevent re-replication by inhibiting the transition of replication origins to a prereplicative state. Curr. Biol. 5: 1257-1269.

Dealy, M.J., K.V.T. Nguyen, J. Lo, M. Gstaiger, W. Krek, D. Elson, J. Arbeit, E. Kipreos, and R.S. Johnson. 1999. Loss of cull results in early embryonic lethality and dysregulation of cyclin E. Nat. Genet. 23: 245-248.

Diehl, J.A., F. Zindy, and C.J. Sherr. 1997. Inhibition of cyclin D1 phosphorylation on threonine-286 prevents its rapid degradation via the ubiquitin-proteasome pathway. Genes \& Dev. 11: 957-972.

Diehl, J.A., M. Cheng, M.F. Roussel, and C.J. Sherr. 1998. Glycogen synthase kinase- $3 \beta$ regulates cyclin D1 proteolysis and subcellular localization. Genes \& Dev. 12: 3499-3511.

Dyson, N. 1998. The regulation of E2F by pRB-family proteins. Genes \& Dev. 12: 2245-2262.

Feldman, R.M., C.C. Correll, K.B. Kaplan, and R.J. Deshaies. 1997. A complex of Cdc4p, Skp1p, and Cdc53p/Cullin catalyzes ubiquitination of the phosphorylated CDK inhibitor Sic1p. Cell 91: 221-230.

Follette, P.J., R.J. Duronio, and P.H. O'Farrell. 1998. Fluctuations in cyclin $\mathrm{E}$ levels are required for multiple rounds of endocycle S phase in Drosophila. Curr. Biol. 8: 235-238.

Freed, E., K.R. Lacey, P. Huie, S.A. Lyapina, R.J. Deshaies, T. Sterns, and P.K. Jackson. 1999. Components of an SCF ubiquitin ligase localize to the centrosome and regulate the centrosome duplication cycle. Genes \& Dev. 13: 2242-2257.

Geng, Y., W. Whoriskey, M.Y. Park, R.T. Bronson, R.H. Medema, T. Li, R.A. Weinberg, and P. Sicinski. 1999. Rescue of cyclin D1 deficiency by knockin cyclin E. Cell 97: 767777.

Hershko, A. and A. Ciechanover. 1998. The ubiquitin system. Annu. Rev. Biochem. 67: 425-479.
Hilton, D.J., R.T. Richardson, W.S. Alexander, E.M. Viney, T.A Willson, N.S. Sprigg, R. Starr, S.E. Nicholson, D. Metcalf, and N.A. Nicola. 1998. Twenty proteins containing a C-terminal SOCS box form five structural classes. Proc. Natl. Acad. Sci. 95: 114-119.

Jiang, J. and G. Struhl. 1999. Regulation of the hedgehog and wingless pathways by the F-box/WD40-repeat protein slimb. Nature 391: 493-496.

Kaelin, W.G., O. Iliopoulos, K.M. Lonergan, and M. Ohh. 1998. Functions of the von Hippel-Lindau tumour suppressor protein. J. Intern. Med. 243: 535-539.

Kamura, T., S. Sato, D. Haque, L. Liu, W.G. Kaelin Jr., R.C. Conaway, and J.W. Conaway. 1998. The Elongin BC complex interacts with the conserved SOCS-box motif present in members of the SOCS, ras, WD-40 repeat, and ankyrin repeat families. Genes \& Dev. 12: 3872-3881.

Kamura, T., D.M. Koepp, M.N. Conrad, D. Skowyra, R.J. Moreland, O. Iliopoulos, W.S. Lane, W.G. Kaelin Jr., S.J. Elledge, R.C. Conaway et al. 1999. Rbx1, a component of the VHL tumor suppressor complex and SCF ubiquitin ligase. Science 284: 657-661.

Kipreos, E.T., L.E. Lander, J.P. Wing, W.W. He, and E.M. Hedgecock. 1996. cul-1 is required for cell cycle exit in C. elegans and identifies a novel gene family. Cell 85: 829-839.

Koepp, D.M., J.W. Harper, and S.J. Elledge. 1999. How the cyclin became a cyclin: Regulated proteolysis in the cell cycle. Cell 97: 431-434.

Kominami, K., I. Ochotorena, and T. Toda. 1998. Two F-box/ WD-repeat proteins Pop1 and Pop2 form hetero- and homocomplexes together with Cullin-1 in the fission yeast SCF (Skp1-Cullin-1-F-box) ubiquitin ligase. Genes Cells 3: 721735

Lanker, S., M.H. Valdivieso, and C. Wittenberg. 1996. Rapid degradation of the $\mathrm{G}_{1}$ cyclin $\mathrm{Cln} 2$ induced by CDK-dependent phosphorylation. Science 271: 1597-1601.

Leone, G., J. DeGregori, L. Jakoi, J.G. Cook, and J.R. Nevins. 1999. Collaborative role of E2F transcriptional activity and G1 cyclindependent kinase activity in the induction of $\mathrm{S}$ phase. Proc. Natl. Acad. Sci. 96: 6626-6631.

Lisztwan, J., G. Imbert, C. Wirbelauer, M. Gstaiger, and W. Krek. 1999. The von Hippel-Lindau tumor suppressor protein is a component of an E3 ubiquitin-protein ligase activity. Genes \& Dev. 13: 1822-1833.

Maniatis, T. 1999. A ubiquitin ligase complex essential for the NF-кB, Wnt/Wingless, and Hedgehog signaling pathways. Genes \& Dev. 13: 505-510.

Marti, A., C. Wirbelauer, M. Scheffner, and W. Krek. 1999. Interaction between the ubiquitin-protein ligase SCFSKP2 and E2F-1 underlies the regulation of E2F-1 degradation. Nat. Cell Biol. 1: 14-19.

Mathias, N., S.L. Johnson, M. Winey, A.E. Adams, L. Goetsch, J.R. Pringle, B. Byers, and M.G. Goebl. 1996. Cdc53p acts in concert with Cdc4p and Cdc34p to control the G1-to-Sphase transition and identifies a conserved family of proteins. Mol. Cell. Biol. 16: 6634-6643.

Ohta, T., J.J. Michel, A.J. Schottelius, and Y. Xiong. 1999. ROC1, a homolog of APC11, represents a family of Cullin partners with an associated ubiquitin ligase activity. Mol. Cell 3: 535-541.

Ohtsubo, M. and J.M. Roberts. 1993. Cyclin-dependent regulation of G1 in mammalian fibroblasts. Science 259: 1908 1912.

Patton, E.E., A.R. Willems, D. Sa, L. Kuras, D. Thomas, K.L. Craig, and M. Tyers. 1998a. Cdc53 is a scaffold protein for multiple Cdc34/Skp1/F-box protein complexes that regulate cell division and methionine biosynthesis in yeast. Genes \& 
Dev. 12: 692-705.

Patton, E.E., A.R. Willems, and M. Tyers. 1998. Combinatorial control in ubiquitin-dependent proteolysis: Don't Skp the F-box hypothesis. Trends Genet. 14: 236-243.

Resnitzky, D. and S.I. Reed. 1995. Different roles for cyclins D1 and E in regulation of the G1-to-S transition. Mol. Cell. Biol. 15: 3463-3469.

Roberts, J.M. 1999. Evolving ideas about cyclins. Cell 98: 129_ 132.

Seol, J.H., R.M. Feldman, W. Zachariae, A. Shevchenko, C.C. Correll, S. Lyapina, Y. Chi, M. Galova, J. Claypool, S. Sandmeyer et al. 1999. Cdc53/Cullin and the essential hrt1 RING-H2 subunit of SCF define a ubiquitin ligase module that activates the E2 enzyme cdc34. Genes \& Dev. 13: 16141626.

Sherr, C.J. and J.M. Roberts. 1999. CDK inhibitors: Positive and negative regulators of $\mathrm{G}_{1}$-phase progression. Genes \& Dev. 13: $1501-1512$.

Singer, J.D., M. Gurian-West, B. Clurman, and J.M. Roberts. 1999. Cullin-3 targets cyclin E for ubiquitination and controls S phase in mammalian cells. Genes \& Dev. 13: 2375 2387.

Skowyra, D., K. Craig, M. Tyers, S.J. Elledge, and J.W. Harper. 1997. F-box proteins are components of E3 complexes and act as receptors to recruit phosphorylated substrates for ubiquitination. Cell 91: 209-219.

Skowyra, D., D.M. Koepp, T. Kamura, M.N. Conrad, R.C. Conaway, J.W. Conaway, S.J. Elledge, and J.W. Harper. 1999. Reconstitution of G1 cyclin ubiquitination with complexes containing SCFGrr1 and Rbx1. Science 284: 662-665.

Spencer, E., J. Jiang, and Z.J. Chen. 1999. Signal-induced ubiquitination of $\mathrm{I} \mathrm{B} \alpha$ by the F-box protein Slimb/ $\beta$-TrCP. Genes \& Dev. 13: 284-294.

Spruck, C.H., K.A. Won, and S.I. Reed. 1999. Deregulated cyclin E induces chromosome instability. Nature 401: 297-301.

Stebbins, C.E., W.G. Kaelin Jr, and N.P. Pavletich. 1999. Structure of the VHL-ElonginC-ElonginB complex: Implications for VHL tumor suppressor function. Science 284: 455-461.

Sutterluty, H., E. Chatelian, A. Marti, C. Wirbelauer, M. Senften, U. Muller, and W. Krek. 1999. p45SKP2 promotes p27Kip1 degradation and induces S phase entry in quiescent cells. Nat. Cell Biol. 1: 207-214.

Tsvetkov, L.M., K.H. Yeh, S.J. Lee, H. Sun, and H. Zhang. p27(Kip1) ubiquitination and degradation is regulated by the SCFSkp2 complex through phosphorylated thr187 in p27. Curr. Biol. 9: 661-664.

Tyers, M. and A.R. Willems. 1999. One ring to rule a superfamily of E3 ubiquitin ligases. Science 284: 601, 603-604.

Wang, Y., S. Penfold, X. Tang, N. Hattori, P. Riley, J.W. Harper, J.C. Cross, and M. Tyers. 1999. Deletion of the Cul1 gene in mice causes arrest in early embryogenesis and accumulation of cyclin E. Curr. Biol. 9: 1191-1194.

Willems, A.R., S. Lanker, E.E. Patton, K.L. Craig, T.F. Nason, N. Mathias, R. Kobayashi, C. Wittenberg, and M. Tyers. 1996. Cdc53 targets phosphorylated G1 cyclins for degradation by the ubiquitin proteolytic pathway. Cell 86: 453-463.

Winston, J.T., D.M. Keopp, C. Zhu, S.J. Elledge, and J.W. Harper. 1999a. A family of mammalian F-box proteins. Curr. Biol. 9: 1180-1182.

Winston, J.T., P. Strack, P. Beer-Romero, C.Y. Chu, S.J. Elledge, and J.W. Harper. 1999b. The SCF ${ }^{\text {TRCP }}{ }^{\text {-ubiquitin ligase }}$ complex associates specifically with phosphorylated destruction motifs in I $\mathrm{I} B \alpha$ and $\beta$-catenin and stimulates IкB $\alpha$ ubiquitination in vitro. Genes \& Dev. 13: 270-283.

Won, K.A. and S.I. Reed. 1996. Activation of cyclin E/CDK2 is coupled to site-specific autophosphorylation and ubiquitin- dependent degradation of cyclin E. EMBO J. 15: 4182-4193.

Won, K.A., R.J. Schumacher, G.W. Farr, A.L. Horwich, and S.I. Reed. 1998. Maturation of human cyclin E requires the function of eukaryotic chaperonin CCT. Mol. Cell. Biol. 18: 7584-7589.

Yaron, A., A. Hatzubai, M. Davis, I. Lavon, S. Amit, A.M. Manning, J.S. Andersen, M. Mann, F. Mercurio, and Y. Ben-Neriah. 1998. Identification of the receptor component of the ІкB $\alpha$-ubiquitin ligase. Nature 396: 590-594.

Zachariae, W., A. Shevchenko, P.D. Andrews, R. Ciosk, M. Galova, M.J. Stark, M. Mann, and K. Nasmyth. 1998. Mass spectrometric analysis of the anaphase-promoting complex from yeast: Identification of a subunit related to Cullins. Science 279: 1216-1219.

Zhang, J.G., A. Farley, S.E. Nicholson, T.A. Willson, L.M. Zugaro, R.J. Simpson, R.L. Moritz, D. Cary, R. Richardson, G. Hausmann et al. 1999. The conserved SOCS box motif in suppressors of cytokine signaling binds to elongins B and C and may couple bound proteins to proteasomal degradation. Proc. Nat1. Acad. Sci. 96: 2071-2076. 


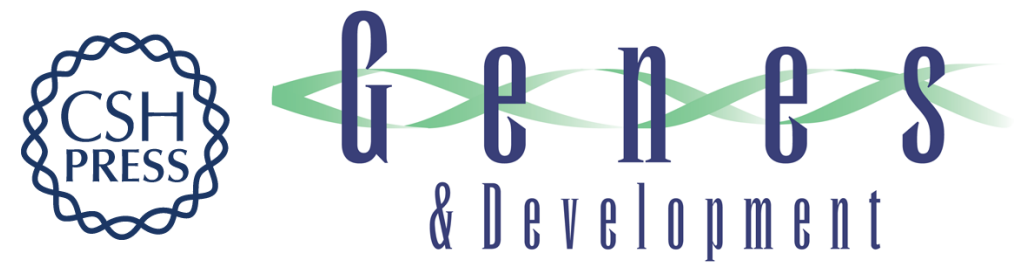

\section{Culprits in the degradation of cyclin E apprehended}

Jeffrey T. Winston, Claire Chu and J. Wade Harper

Genes Dev. 1999, 13:

References This article cites 54 articles, 27 of which can be accessed free at: http://genesdev.cshlp.org/content/13/21/2751.full.html\#ref-list-1

License

Email Alerting

Receive free email alerts when new articles cite this article - sign up in the box at the top Service right corner of the article or click here.

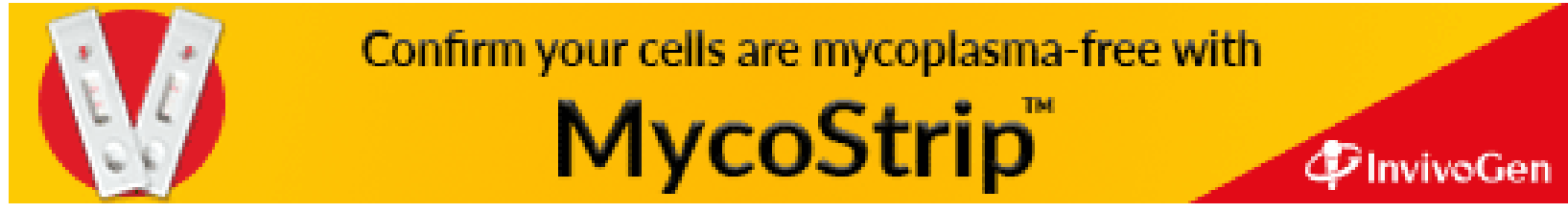

